\title{
Does Social Value Orientation Theory Apply to Social Relations?
}

\author{
Patricia Danielle Lewis, David Willer
}

University of South Carolina

\begin{abstract}
This research asks whether Social Value Orientations (SVOs) apply to the social relations of exchange networks. SVO literature identifies three types of orientation to rational action, determined by how actors value outcomes to self and other. Only the individualist is the self-interested, rational actor previously seen in exchange networks. The prosocial actor seeks to maximize joint outcomes and equality whereas the competitor seeks to maximize differences between self and other. The competitor and individualist are frequently collapsed into a proself type. Whereas SVO research has focused on games and social dilemmas, this research places prosocials and proselfs in equal, weak, and strong power exchange structures. We show that, if SVO applies, the behaviors of proself and prosocial will be very different. Experimental results demonstrate, however, that prosocials' actions in exchanges are indistinguishable from activities of proselfs.
\end{abstract}

Keywords: theoretical scope; social values; social relations; individualist; prosocial

Citation: Lewis, Patricia Danielle, and David Willer. 2017. "Does Social Value Orientation Theory Apply to Social Relations?" Sociological Science 3: 249-262.

Received: December 19, 2016

Accepted: January 11, 2017

Published: March 29, 2017

Editor(s): Jesper Sørensen, Sarah Soule

DOI: $10.15195 / \mathrm{v} 4 . \mathrm{a} 11$

Copyright: (C) 2017 The Author(s). This open-access article has been published under a Creative Commons Attribution License, which allows unrestricted use, distribution and reproduction, in any form, as long as the original author and source have been credited. @()
THIS article investigates the scope of Social Value Orientation theory and whether 1 it applies to social relations (Walker and Cohen 1985). Previous applications of that theory have clearly shown that people with contrasting value orientations behave very differently in games and social dilemmas (Bogaert, Boone, and Declerck 2008). We seek to determine whether the behavior of people with contrasting value orientations differs when they are embedded in social relations of exchange and exchange structures. Fortunately, metric predictions have already been generated (Willer, Gladstone, and Berigan 2013), predictions that see those with contrasting value orientations as behaving quite differently. Therefore, the predictions are testable and will be experimentally tested here.

As recently as two decades ago, a leading game theorist and experimental economist, Alvin Roth, could confidently assert that application of the rational, self-interested actor offers a "useful approximation of behavior" (1995:78). Roth was not alone. In asserting the utility of the rational, self-interested actor, he was in agreement with economic thinking as wide ranging as macroeconomics and microlevel game theory as well as the traditions of the two back to Adam Smith ([1776] 1937) and Von Neumann and Morgenstern ([1944] 2004), respectively. Nor has the rational, self-interested actor been confined to economics. In the form of "rational choice" it has impacted sociological theory (Coleman and Fararo 1992; Hechter 1987), including exchange theory in its diverse forms (Willer and Emanuelson 2008).

While self-interested, rational actor models were being adopted in sociology, a new tradition of research, Social Value Orientations, was developing to challenge the assumption of the self-interested actor. Unlike the "norm-regarding" actor of Parsons (1937; Parsons and Shils 1951) that is thought by some to still pervade 
sociology (Fehr and Gintis 2007), researchers in Social Value Orientations (hereafter SVOs) deploy not a single actor, but three. The three actors, all of which are rational, are called individualist, prosocial, and competitor.

Studied across a number of disciplines, SVOs were developed to (1) dispel the common perception of human beings as necessarily motivated by self-interest, and (2) provide insight into other-regarding behavior occurring in experimental games (Messick and McClintock 1968). SVOs are preferences for how outcomes are distributed between self and other in interdependent situations (Liebrand 1986; Liebrand and McClintock 1988; Kollock 1998). According to SVO researchers, "different individuals assign different weights to their own and to others' outcomes. These weights effectively define an actor's social value orientation" (Liebrand and McClintock 1988:397).

Bogaert et al. give these definitions for the three value orientations. Prosocials "strive to maximize joint outcomes and equality in outcomes." Individualists "strive to maximize their own outcome only." Competitors "strive to maximize their own gains relative to other's gains" (2008:456). The individualist is the self-interested, rational actor, whereas prosocial and competitor are new. A meta-analysis conducted by Au and Kwong (2004) found that 86.6 percent of subjects in published experiments are classifiable as one of the three SVOs: individualists 23.5 percent, prosocials 49.7 percent, and competitors 13.4 percent.

Do SVO formulations apply to social relations and structures? Previous SVO research does not answer that question. Still, the impressive range of research supporting SVO applications suggests that SVO should apply to social relations and structures in which individualists and prosocials should behave very differently. On the other hand, by living in capitalist societies dominated by social relations of exchange, individualists and prosocials have very different behaviors predicted for them that should stand out; the differences should be seen every day. But are they? If they did, SVO formulations should have impacted modern economic theory, but they have not. SVO formulations have had no impact on mainstream macroeconomics (Mankiw 2015) or microeconomics (Krugman and Wells 2012). Nevertheless, whether SVO formulations apply to social relations cannot be answered with the evidence now in hand. Experimental research newly offered here answers whether SVO theory explains and predicts in this significant range of human behavior.

\section{Previous SVO Research: An Overview}

Here, we review some previous SVO research in order to indicate the range of phenomena to which SVO formulations have been applied. When $\mathrm{U}_{i}$ is $i^{\prime}$ s utility, $P_{i}$ is $i$ 's payoff, and $P_{j}$ is the payoff to the other, the three Social Value Orientations defined by Bogaert et al. (2008) are:

$$
\begin{gathered}
\text { Individualist : } U_{i}=P_{i} \\
\text { Competitor : } U_{i}=P_{i}-P_{j}
\end{gathered}
$$


Research on social values has shown that these preferences predict a wide range of behaviors in experimental settings such as collective good games and in everyday settings such as commuting choices and willingness to sacrifice in relationships (Van Lange et al. 1997; Liebrand 1986; Bekkers 2003). ${ }^{1}$

Uses of SVO theory in sociology are well illustrated in two recent studies. Simpson (2004) asks how people with contrasting SVOs play the prisoner's dilemma (PD) game. Prosocials should be more cooperative than individualists. But why? As will be remembered, the highest payoff to self in the PD game is to defect when the other cooperates (DC), whereas the second highest is to cooperate when the other cooperates (CC). Because the payoffs are DC $>C C$, game theory predicts that players will always defect in the one-shot PD. ${ }^{2}$ However, Simpson predicts that whereas individualists play the game as just described, prosocials will transform the payoffs such that $\mathrm{CC}>\mathrm{DC}$, thus producing cooperation. In his two experiments, the PD game was played simultaneously and sequentially. In the simultaneous game, the experimental subject did not know the other's choice when making his or her own. In the sequential game, the experimental subject played second and knew that the other had cooperated. In both experiments, prosocials cooperated more and did so because they subjectively transformed the game's payoff matrix.

In the second study, Harrell and Simpson (2015) compared social dilemmas in which an individualist or prosocial was selected as a leader with the power to punish. They found that, contrary to Fehr and Gintis (2007), individualists and prosocials did not differ in frequency of punishment, but they differed in amounts contributed. Prosocials contributed more than individualists. Furthermore, after promotion to leader, prosocials increased their contributions, but individualists decreased their contributions.

In summary, SVO research's strongest empirical support has occurred in decision situations in which benefits to self and other are readily identifiable. Beyond oneshot PD games, these include the dyadic ultimatum game in which self makes an offer that can only be accepted or rejected by other and the dictator game in which other receives the amount dictated by self. They also include public goods games like those studied by Harrell and Simpson, in which self and others face similar decision situations. Notable by their absence are decision situations that follow the give and take of negotiations and decision situations in which experimental subjects occupy different social positions, including those in which there can be multiple others.

\section{Embedding SVOs in Social Exchange Relations}

Using resistance Network Exchange Theory (hereafter NET) makes metric predictions for exchange ratios in various structures. The actor is modeled as balancing its 
interest in gaining the best possible payoff with its interest in avoiding confrontation, in which no exchange is completed (Willer 1984; Willer and Emanuelson 2008). Where $P i$ is $i$ 's payoff, $P i_{\text {max }}$ is $i$ 's maximum payoff (i's best hope), and $P i_{c o n}$ is $i^{\prime}$ 's the payoff at confrontation when agreement is not reached,

$$
R i=\frac{P i_{\max }-P i}{P i-P i_{\text {con }}}
$$

For any given $P i_{\max }$ and $P i_{c o n}$, when the payoff to $i$ is high, the actor's resistance will be low. By contrast, low payoffs produce high resistance.

To integrate SVOs into resistance, we substitute utility for payoff:

$$
R i=\frac{U i_{\max }-U i}{U i-U i_{c o n}}
$$

when $i$ is an individualist, and $i$ 's and $j^{\prime}$ s payoffs sum to 10,

$$
R_{I i}=\frac{9-P i}{P i-0}
$$

when $i$ is prosocial,

$$
R_{P i}=\frac{10-(P i+P j-|P i-P j|)}{P i+P j-|P i-P j|-0}
$$

and when $i$ is a competitor,

$$
R_{\mathrm{Ci}}=\frac{8-(P i-P j)}{P i-P j-0}
$$

$P_{\max }=9$ for the individualist because that is the largest payoff when $=1, P_{\max }=10$ for the prosocial when that actor and its partner both gain 5, and $\mathrm{P}_{\max }=8$ for the competitor when the competitor gains the maximum of 9 and its partner's payoff of 1 is subtracted. To solve for $i$ and $j$ payoffs in a dyad for any combination of SVOs, the two actors' resistances are set equal to each other. For example, for individualist A and prosocial B,

$$
\frac{9-P_{A}}{P_{A}-0}=\frac{10-\left(P_{B}+P_{A}-\left|P_{B}-P_{A}\right|\right)}{P_{B}+P_{A}-\left|P_{B}-P_{A}\right|-0}
$$

Because $\mathrm{P}_{A}+\mathrm{P}_{B}=10$, substituting, $\mathrm{P}_{A}=6.43$ and $\mathrm{P}_{B}=3.57$. This outcome is a power exercise because the individualist benefits at the expense of the prosocial (Cook et al. 1983; Willer 1999). ${ }^{3}$

\section{Experimental Design and Results}

In this section, we will first describe the research methods employed. Having measured participants' SVOs, they were placed into equal power dyads, the strong power Br31, or the weak power 4-Line. Figure 1 displays these networks. The conditions, hypotheses, and exchange ratio results for each structure are discussed separately. We also discuss how, as the research progressed, we included a one-shot 
A. Dyad

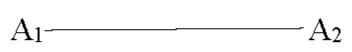

C. 4-Line
B. $\operatorname{Br} 31$

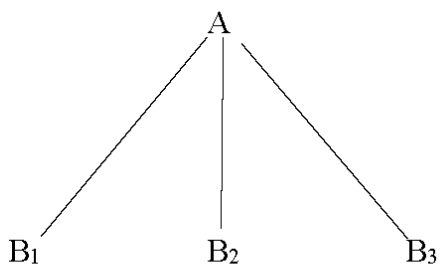

$\mathrm{B}_{2}$

$\mathrm{A}_{1} \longrightarrow \mathrm{B}_{1} \longrightarrow \mathrm{B}_{2} \longrightarrow \mathrm{A}_{2}$

Figure 1: Structures used in exchange experiments.

dictator game immediately prior to and following the exchange rounds to check measures of SVOs.

\section{Methods}

Participants were undergraduates enrolled at a large state university. The NineItem Social Value Inventory was used to measure SVO (McClintock et al. 1973; Van Lange 1999). The measure asks participants to decide how payoffs should be divided between the self and other. Nine scenarios are given, each with three options. A score of seven consistent responses out of nine was required to identify a participant as a prosocial, individualist, or competitor; seven is one more than commonly employed in SVO research (McClintock and Allison 1989; Van Lange and Kuhlman 1994; Van Lange et al. 1997). Those with a consistent score were contacted for the lab portion of the study. 
Because the Nine-Item Inventory could be taken in a classroom or online, the time between the inventory and experiment could vary across participants. Given the understanding, common across the SVO literature, that people's SVOs are stable over time, the design is sound. Nevertheless, as the research went forward, further measures of SVO were instituted. The dictator game was given in the laboratory immediately prior to and immediately after the exchange experiment. Having found that 53.2 percent of males and 52.9 percent of females were prosocial, SVO type, not gender, was used to assign participants to positions.

In the lab, participants were placed in individual rooms and read experimental instructions. Unlike all prior NET experiments in which an individualist orientation was produced by instructing participants to earn as many points for themselves as possible, here, instructions suggested to negotiate "as you see fit."

Seated at individual PCs, participants interacted through ExNet, which allowed them to view a live display of the complete network. A tutorial taught participants to use mouse control to make offers, counteroffers, and complete exchanges. After completing the tutorial, participants began the exchange portion, in which they negotiated with each other. As in previous NET research, we utilized full information conditions. Participants were able to view the full structure in which they were participating as well as all offers, counteroffers, and completed exchanges between all positions in real time. All sessions followed the "1-exchange rule," in which each participant could complete a maximum of one exchange per round. ${ }^{4}$ Each experimental session lasted 10 to 20 rounds.

As in most NET experiments, resource pools, lumpy in units of one, were located between connected positions. Payoffs occurred when participants agreed on a division of the pool (Cook and Emerson 1978; Willer and Emanuelson 2008). For this investigation, the number of resources in the pool was changed from 24 to 37 in order to avoid "priming effects" for equity; 24 is obviously divisible by 2 , but 37 is not. Nevertheless, exchange is a repeated game; subjects could attain equity by successive 18 - 19 and 19 - 18 divisions. Upon conclusion of the exchange sessions, participants were paid by points earned, and their questions about the research were answered.

For the research, participants of one or another SVO type were placed into one or another kind of position in a structure. Individualists and competitors were collapsed into a single type, proself (De Cremer and Van Lange 2001; Smeesters et al. 2003; Simpson 2004; Simpson and Willer 2008; Balliet, Parks, and Joireman 2009). ${ }^{5}$ Thus, there were two SVO types to allocate. For the dyad, in which there are two identical positions, we studied all three pairings: proself-proself, prosocialprosocial, and proself-prosocial types. For Br31 and the 4-Line, there are two types of positions and two SVO types. For this investigation, one SVO type occupied of one kind of position and the other SVO type occupied the other type of position, with the reverse giving two types. ${ }^{6}$

\section{Dyads}

Dyads are equal power in that neither position is advantaged. Thus, exchanges result in equal division of resources unless pairs of participants carry different 
conditions (such as differing SVOs) with them into the exchange that affect results (Willer 1999).

Hypotheses. Here and below, all hypotheses assume that SVO types will have distinct effects in social exchange relations, just as they have had in previous SVO research on games and social dilemmas. Embedding identical SVO types into the resistance equation for the dyad produces a prediction of equal resource divisions. For different SVOs, proselfs are predicted to earn more than half of the resource pool when paired with prosocials. Employing the equation shown in the previous section, the resistance solution for this pairing is a 25.25-point payoff for the proself and 11.75 points for the prosocial. This prediction is consistent with previous SVO literature that suggests that prosocials are subject to exploitation by proselfs.

H1: Identical dyadic pairs will exchange equally, with each actor receiving 18.5 points on average.

H2: Prosocials and proselfs in the dyad will earn average payoffs of 11.75 and 25.25 points, respectively.

Results. Participants in all dyads earned average payoffs nearly identical to equal power payoffs. Hypothesis 1 was supported. Neither the mean payoff for prosocial pairs $(\mathrm{M}=18.72, n=10, \mathrm{SD}=0.74, p=0.37, t=0.94)$ nor the mean payoff for proself pairs $(\mathrm{M}=18.86, n=10, \mathrm{SD}=1.39, p=0.43, t=0.83)$ was significantly different from the predicted mean of 18.5. Hypothesis 2 predicts SVO effects to alter conditions within the dyad; this hypothesis was not supported. The observed mean for prosocials paired with proselfs $(\mathrm{M}=18.56, n=21, \mathrm{SD}=2.08)$ was significantly different from the predicted 11.75 payoff $(p<0.0001, t=15.00)$, but is not different from equal power payoffs $(p=0.89, t=0.13)$. SVO effects were absent in the dyad. ${ }^{7}$

\section{Br31 Structures}

The Br31 is a strong power structure with two types of positions: the central position, which can never be excluded, and the three peripherals, two of which will be excluded. In previous research, the risk of exclusion drove competition among peripheral positions that pushed payoffs to the central position toward the extreme (Willer 1999).

Hypotheses. Because prosocials prefer equal payoffs, when occupying the central, high-power position, prosocials should resist exploiting the peripherals. Being high in power, they can dictate equal payoffs to those in peripheral positions regardless of their SVOs. Though low-power actors may drive strong power structures toward the extreme, Willer et al. (2013:124) predicted that "the central prosocial uses its power position to impose equality" (italics in original). Proselfs, not subject to concern for others, should gain payoffs higher than equality and near the extreme of the negotiation set regardless of the SVOs of peripherals.

H3: Prosocial centrals should receive an average payoff of 18.5 .

H4: Proself centrals should receive an average payoff significantly higher than 18.5 . 
Results. We examined the following four structural configurations: (1) pure prosocial (prosocial central with all prosocial peripherals), (2) a prosocial central with all proself peripherals, (3) pure proself, and (4) a proself central with all prosocial peripherals. Because only the orientation of the central position should affect outcomes, we collapsed the four configurations into two, based on the type of central (prosocial or proself). ${ }^{8}$

Prosocial centrals earned an average of 25.01 points $(n=20, \mathrm{SD}=5.09)$. A onesample $t$ test showed a significant difference from the predicted $18.5(p<0.0001, t=$ 5.72). This finding does not support hypothesis 3 . As a follow-up test, we conducted a $t$ test to compare the prosocial centrals' observed mean to the observed mean for proself centrals $(\mathrm{M}=27.69, n=14, \mathrm{SD}=4.49)$. This difference was not statistically significant $(p=0.12, t=1.59)$. To test hypothesis 4 , we used a one-sample $t$ test to compare the observed proself central mean to the predicted prosocial payoff. A significant difference $(p<0.0001, t=7.66)$ supported this hypothesis.

Taken together, these findings do not support predicted SVO effects. Proself power exercises are predicted by NET for strong power structures. Strong power exercised by prosocial centrals as observed is, however, a departure from SVObased predictions. Their exploitation of peripherals is indistinguishable from that of proselfs.

\section{4-Line Structures}

The 4-Line is a weak power structure. The central B positions are never excluded from exchange, but the peripheral A positions are excluded if the Bs exchange with each other. Thus, resource divisions fall between equal divisions of equal power structures and extremes of strong power structures (Markovsky et al. 1993).

Hypotheses. To find whether central prosocials were less exploitative than central proselfs, two configurations were investigated: (1) central prosocials with peripheral proselfs and (2) central proselfs with peripheral prosocials. We predict that proself centrals in the 4-Line should earn higher payoffs than prosocial centrals. Following our argument regarding strong power structures, we expect proselfs to exploit when possible and prosocials to seek (and enforce) more equal resource divisions.

H5: Proself centrals should earn a higher average payoff than prosocial centrals.

Results. For each experimental run, we combined the mean payoffs for both central positions into one overall mean payoff. Our findings do not support hypothesis 5. The observed mean of $18.91(n=11, \mathrm{SD}=1.15)$ for central prosocials was not significantly different $(p=0.13, t=1.57)$ from the observed mean of 19.69 for proself centrals $(n=11, \mathrm{SD}=1.18)$. Regardless of the SVO configuration, participants occupying the same positions earned similar payoffs. The results for the 4-Line provide further evidence that SVO effects in exchange networks rarely, if ever, occur.

\section{Interaction Processes}

In addition to investigating exchange payoffs, we explored differences in the negotiation processes. To focus only on exchange looks past the series of offers and 
counteroffers preceding the completed exchange. To check for negotiation differences between SVOs, we first compared "actions." ExNet records all offers and completed exchanges; each offer, counteroffer, and agreement is recorded as a separate "action." To compare configurations within each structure type, we counted the number of actions per experimental session and calculated means for each group. Additionally, we compared the timing of rounds and examined first offers in the dyad. Below, we first review the action comparisons within the dyads and 4-Lines and then discuss the tests of first offers and time to complete an exchange in the dyads.

Dyads. In the dyad, we have not found differences in resource divisions between SVO combination types. Nevertheless, differences in the negotiation process are also predicted Prosocials should more quickly agree with less bargaining than proselfs.

H6: The number of actions in the negotiation process ranked from least to most is predicted to be: prosocial-prosocial, prosocial-proself, and proself-proself.

Paired prosocials had the fewest actions: $145(n=11, \mathrm{SD}=69.14)$. Prosocialproself dyads averaged 167 actions $(n=26, \mathrm{SD}=60.41)$. Proself-proself dyads had the highest actions, with a mean of 186 actions $(n=12$, SD $=102.33)$. A comparison of the two types of pure structures was not significant $(p=0.28, t=1.09)$. Neither the actions in the pure prosocial structures $(p=0.36, t=0.92)$ nor the actions in the pure proself structures $(p=0.47, t=0.72)$ were significantly different from the actions in the mixed structures. Though results are not strong enough to support the hypothesis, they are in the predicted direction and underscore the fact that predicted SVO differences, if they occur, are only weakly present. They also suggest that in spite of lack of effect insofar as exchange ratios are concerned, experimental participants did bring contrasting SVOs into the experiment.

4-Lines. We expected findings similar to those predicted for the dyad. Prosocials should not require as many actions as proselfs to reach agreements. We expect that prosocial central Bs will not seek to exercise power but instead maintain equal power dyadic relations.

H7: Structures with prosocial centrals have fewer negotiations than structures with proself centrals.

We found weak support for the hypothesis. Structures with prosocial centrals averaged 296.52 actions per session $(n=19, \mathrm{SD}=119.50)$. Structures with proself centrals averaged 397.00 actions per session $(n=15, \mathrm{SD}=196.77)$. These means being marginally different in the predicted direction $(p=0.07, t=1.84)$ may show a weak SVO effect. Again, as in the dyad, this result indicates that subjects did bring contrasting SVOs into the experiment.

Supplemental Dyad Analyses: Timing and First Offers. Along with actions, ExNet records the time in seconds for each event within each round of exchange. After finding no robust differences between dyad actions, we examined the average time in seconds for completed exchange rounds. Pure proself pairs averaged 61.7 seconds per completed round $(n=10, \mathrm{SD}=38.20)$. Pure prosocial pairs averaged 
50.57 seconds $(n=10, \mathrm{SD}=37.70)$, and mixed pairs completed exchange at an average of 66.4 seconds $(n=21, \mathrm{SD}=31.95)$.

We conducted the three possible $t$ tests, finding no significant differences in timing. Time to complete rounds in prosocial pairs was neither significantly different from time in proself pairs ( $p=0.52, t=0.66$ ) nor from time to complete rounds in mixed pairs $(p=0.23, t=1.22)$. Proself pairs and mixed pairs were also not significantly different in time to complete rounds $(p=0.72, t=0.35)$.

To analyze the first offer in each round of exchange, we noted the SVO of the participant making the offer and the points he or she proposed to earn in the offer. We compared all prosocials' offers to all proselfs' offers across the three types of dyads. When making a first offer to their exchange partners, prosocials proposed to keep a mean of 20.43 out of 37 points $(n=35, \mathrm{SD}=2.27)$. When proselfs made the first offer, they proposed to keep 20.75 points out of 37 on average $(n=37, \mathrm{SD}=$ 2.57). A $t$ test found that this difference was not significant $(p=0.57, t=0.57)$.

Within the mixed pair dyads, we also compared how often prosocials and proselfs conceded (accepted the partner's offer and completed the round of exchange). Prosocials conceded in 52 percent of the rounds, whereas proselfs conceded in 48 percent of the rounds; this difference was not significant $(p=0.47, t=0.72)$.

\section{Dictator Games}

Because of varying times between the completion of the Nine-Item Social Value Inventory and the lab portion of the study, as the research progressed we introduced a one-shot dictator game just prior to the tutorial as an additional SVO measure ( $n$ $=79$ ). A posttest, one-shot dictator game was added to check for potential effects of the exchange game on orientation $(n=333)$. We also gave the dictator game to participants who were scored by the Nine-Item measure but did not participate in the lab portion of the study $(n=94)$. This was done as a check for experimental effects on SVO. Along with the Nine-Item measure, the dictator game has been used as a standard assessment of SVO (Fisman, Kariv, and Daniel Markovits 2007; Simpson and Willer 2008).

In the dictator game, a player is given an endowment of resources and decides how these resources should be divided with another person. The recipient is passive and has no role in the decision. In our experiment, each participant played a paperand-pencil one-shot game. The directions informed each participant that he or she had been given 37 points to be kept or shared with another person. Any amount between 0 and 37 could be chosen; the recipient would never know the identity of the chooser. For all dictator games, choosers were paid the amount kept for self. We expected prosocials to give more points than proselfs.

Results. We ran a Pearson correlation on the dictator game results of participants who completed both the pretest and posttest games $(n=79)$ and found $r=0.77$ between points given in the pretest and points given in the posttest, suggesting that participants' preexperiment SVOs were altered only marginally by the exchange game. In the posttest Dictator Game, prosocials gave $\mathrm{M}=14.06(n=187, \mathrm{SD}=8.47)$ which was significantly more points $(p<0.0001, t=4.95)$ than proselfs $\mathrm{M}=9.18(n$ $=146, \mathrm{SD}=9.47)$. For participants not in the experiment, prosocials in the dictator 
game gave $\mathrm{M}=15.89(n=46, \mathrm{SD}=7.12)$ whereas proselfs gave $\mathrm{M}=9.71(n=48, \mathrm{SD}$ =9.52); the difference was significant $(p=0.0006, t=3.55)$. We note the similarity between subjects who did and did not participate in the experiment. These results strongly suggest that participants' SVOs persisted through the exchanges of the experiment and yet did not significantly affect behavior when exchanging.

\section{Discussion: Prosocial Activity in Exchange Networks}

Previous research in SVO has firmly established that social values produce very strong effects in various games and social dilemmas (Bogaert et al. 2008; De Cremer and Van Lange 2001; McClintock and Liebrand 1988; Simpson and Willer 2008; Van Lange 1999). Yet, following the standard procedures for assessing SVO, excepting possible effects in one of eight tested interaction processes, ${ }^{9}$ we found no SVO effects in exchange networks.

Our results do not lead us to criticize previous SVO research, which we see as well founded. Nor should previous SVO research lead to doubts about our results, for they were found in an experimental setting that has been used hundreds of times to test exchange theories.

Instead, following Walker and Cohen (1985), this research concludes that the SVO theoretic should be limited in scope to exclude economic exchange. Nor should this result be entirely surprising. Living in a capitalist society, it would indeed be surprising to see strongly contrasting prosocial and proself behavior occurring in everyday exchanges that pervade society.

The goal of this research was to find whether SVO theory applies to social relations and structures. We have shown that it does not. Could that theory be revised to extend its scope? To answer that question, one needs first to know why SVO does not apply and for that we suggest that further research is needed. A number of new issues will need to be taken up. For example, in contrast to the exchange relations employed here, strategy space of dilemmas can be very small, as small as two alternatives: cooperate or defect. Given the greater complexity of prosocials' utility function, is the space of social exchange too large for prosocials to act prosocially? Dilemmas are typically played as games; no pregame communication is allowed. Do negotiations dampen out prosociality? Do exchange relations and structures have framing effects that dampen out prosociality? These are but three suggestions. To answer why SVO does not apply will require a much more extensive research project than the one reported here.

\section{Notes}

1 At this point, it would be good to give a precise meaning for the term "utility" and to examine its usage. Although fundamental to economic theory, the meaning of utility itself is surprisingly elusive. Offering no definition of their own, Luce and Raiffa (1957) defer to von Neumann and Morgenstern, who do no more than suggest that utility and "satisfaction" have the same meaning ([1944] 2004:8).

2 As Axelrod (1980a, 1980b) has shown, when iterated, strategies such as tit-for-tat can result in cooperation for the two-person PD game. 
3 Predictions for SVOs in structures studied here and for others were derived by Willer et al. (2013). We are indebted to Carter Butts, who first noticed that resistance equations relating prosocials to individualists or competitors, because of the absolute value factor, potentially have two solutions. Here, there is only one noncontradictory solution: it is given above.

4 The 1-exchange condition has been used in most exchange research. For this condition as a scope limitation, see Willer and Emanuelson (2008).

5 Collapsing competitors and individualists into a single type was justified by two reasons. First, it is common practice to do so in the SVO literature. Second, the number of competitors in the general population and among our participants is very small.

6 As seen below, the two types thus constituted should give the greatest contrast insofar as exchange ratios are concerned.

7 Frequently, we test with relatively small cell sizes and large standard deviations, both of which affect significance of findings. Nevertheless, the finding here that prosocial-proself differences are absent is not affected by either.

8 Prosocial centrals with prosocial peripherals earned an average of 24.57 points $(n=10)$. Prosocial centrals with proself peripherals earned an average of 25.44 points $(n=10)$. Proselfs with proself peripherals earned 26.27 points on average $(n=3)$. Proself centrals with prosocial peripherals earned an average of 28.08 points $(n=11)$. The relevant similarities of means support collapsing to two types.

9 Of the eight tests, only one attained the 0.07 level. Because there is a better than $50 \%$ likelihood that one of the eight tests would attain that level by chance alone, we consider this result a "possible" effect.

\section{References}

Axelrod, Robert. 1980a. "Effective Choice in the prisoner's Dilemma Game." Journal of Conflict Resolution 24:3-25. https://doi .org/10.1177/002200278002400301

Axelrod, Robert. 1980b. "More Effective Choice in the prisoner's Dilemma Game." Journal of Conflict Resolution 24:379-403. https: //doi .org/10.1177/002200278002400301

Au, Wing Tung, and Jessica Kwong. 2004. "Measurements and Effects of Social Value Orientation in Social Dilemmas." Pp 71-98 in R. Sulieman, D.V. Budescu, I. Fischer, and D.M. Messick (eds.) Contemporary Psychological Research on Social Dilemmas. London: Cambridge University Press.

Balliet, Daniel, Craig Parks, and Jeff Joireman. 2009. "Social Value Orientation and Cooperation in Social Dilemmas: A Meta-Analysis." Group Processes and Intergroup Relations 12:533-547. https://doi .org/10.1177/1368430209105040

Bogaert, Sandy, Christopher Boone, and Carolyn Declerck. 2008. "Social Value Orientation and Cooperation in Social Dilemmas: A Review and Conceptual Model". British Journal of Social Psychology 47: 453-480. https: //doi .org/10.1348/014466607X244970

Coleman, James, and Thomas Fararo. 1992. Rational Choice Theory: Advocacy and Critique. Newbury Park: Sage Publications.

Cook, Karen S., and Richard Emerson. 1978. "Power, Equity and Commitment in Exchange Networks." American Sociological Review 43: 721-739. https : //doi .org/10 . 2307/ 2094546 
Cook, Karen S., Richard M. Emerson, Mary R. Gillmore, and Toshio Yamagishi. 1983. "The Distribution of Power in Exchange Networks: Theory and Experimental Results." American Journal of Sociology 89:275-305. https : //doi . org/10.1086/227866

De Cremer, David, and Paul A. M. van Lange. 2001. "Why Prosocials Exhibit Greater Cooperation than Proselfs: The Roles of Social Responsibility and Reciprocity." European Journal of Personality 15:5-18. https : //doi . org/10.1002/per . 418

Fehr, Ernst, and Herbert Gintis. 2007. "Human Motivation and Social Cooperation: Experimental and Analytical Foundations." Annual Review of Sociology 33: 43-64. https: //doi.org/10.1146/annurev.soc.33.040406.131812

Fisman, Raymond, Shachar Kariv, and Daniel Markovits. 2007. "Individual Preferences for Giving." The American Economic Review 97: 1858-1876. https://doi .org/10.1257/aer . 97.5 .1858

Harrell, Ashley, and Brent Simpson. 2015 "The Dynamics of Prosocial Leadership: Power and Influence in Collective Action Groups." Social Forces 2-26.

Hechter, Michael. 1987. Principles of Group Solidarity. Berkeley: University of California Press.

Kollock, Peter. 1998. "Social Dilemmas: The Anatomy of Cooperation". Annual Review of Sociology 24: 183-214. https://doi.org/10.1146/annurev.soc.24.1.183

Krugman, Paul, and Robin Wells. 2012. Microeconomics. New York: Worth Publishers.

Liebrand, W.B.G. 1986. "The Ubiquity of Social Values in Social Dilemmas". Pp. 113-33 in H. Wilke, D. Messick, \& C. Rutte. (eds.) Experimental Social Dilemmas. Frankfort Germany: Peter Lang. https://doi .org/10.1002/per.2410020304

Liebrand, Wim B. G., and Charles G. McClintock. 1988. "The Ring of Social Values: A Computerized Procedure for Assessing Individual Differences in Information Processing and Social Value Orientation". European Journal of Personality 2: 217-230.

Mankiw, N. Gregory. 2015. Macroeconomics. New York: Macmillan.

Markovsky, Barry, John Skvoretz, David Willer, Michael Lovaglia, and Jeffrey Erger. 1993. "Seeds of Weak Power: An Extension of Network Exchange Theory." American Sociological Review 58:197-209. https://doi.org/10.2307/2095966

McClintock, Charles G., and Scott T. Allison. 1989. "Social Value Orientation and Helping Behavior." Journal of Applied Social Psychology 19:353-362. https ://doi .org/10.1111/ j.1559-1816.1989.tb00060.x

McClintock, Charles G., and Wim B.G. Liebrand. 1988. "Role of Interdependence Structure, Individual Value Orientation, and Another's Strategy in Social Decision Making: A Transformational Analysis." Journal of Personality and Social Psychology 55:396-409. https : //doi.org/10.1037/0022-3514.55.3.396

McClintock, Charles, David Messick, David Kuhlman, and Francis Campos. 1973. "Motivational Bases of Choice in Three-choice Decomposed Games." Journal of Experimental Social Psychology 9:572-590. https : //doi .org/10.1016/0022-1031 (73)90039-5

Messick, David M., and Charles McClintock. 1968. "Motivational Basis of Choice in Experimental Games." Journal of Experimental Social Psychology 4:1-25. https : //doi .org/10 . 1016/0022-1031(68) 90046-2

Parsons, Talcott. 1937. The Structure of Social Action. New York: McGraw-Hill.

Parsons, Talcott, and Edward Shils. 1951. Toward a General Theory of Action. Cambridge MA: Harvard University Press. https://doi .org/10.4159/harvard. 9780674863507

Roth, Alvin E. 1995. "Introduction." Pp. 3-20 in John H. Kagel and Alvin E. Roth. (eds.) The Handbook of Experimental Economics. Princeton NJ: Princeton University Press. 
Simpson, Brent. 2004. "Social Values, Subjective Transformations, and Cooperation in Social Dilemmas." Social Psychology Quarterly 67:385-95. https://doi.org/10.1177/ 019027250406700404

Simpson, Brent, and Robb Willer. 2008. "Altruism and Indirect Reciprocity: The Interaction of Person and Situation in Prosocial Behavior." Social Psychology Quarterly 71:37-52. https : //doi.org/10.1177/019027250807100106

Smeesters, Dirk, Luk Warlop, Eddy Van Avermaet, Olivier Corneille, and Vincent Yzerbyt. 2003. "Do Not Prime Hawks with Doves: The Interplay of Construct Activation and Consistency of Social Value Orientation on Cooperative Behavior." Journal of Personality and Social Psychology 84:972-87. https : //doi .org/10.1037/0022-3514 .84 .5 .972

Smith, Adam. [1776] 1937. The Wealth of Nations. New York: The Modern Library.

Van Lange, Paul A.M. 1999. "The Pursuit of Joint Outcomes and Equality in Outcomes: An Integrative Model of Social Value Orientation." Journal of Personality and Social Psychology 77:337-349. https://doi .org/10.1037/0022-3514.77.2.337

Van Lange, P. A. M., and D. M. Kuhlman. 1994. "Social Value Orientations and Impressions of Partner's Honesty and Intelligence: A Test of the Might versus Morality Effect." Journal of Personality and Social Psychology 67:126-141. https://doi .org/10.1037/0022-3514. 67.1 .126

Van Lange, Paul A. M., Wilma Otten, Ellen N. M. De Bruin, and Jeffrey A. Joireman. 1997. "Development of Prosocial, Individualistic, and Competitive Orientations: Theory and Preliminary Evidence." Journal of Personality and Social Psychology 73: 733-746. https: //doi.org/10.1037/0022-3514.73.4.733

Von Neumann, John, and Oskar Morgenstern. [1944] 2004. Theory of Games and Economic Behavior. Princeton, NJ: Princeton University Press.

Walker, Henry A., and Bernard P. Cohen. 1985. "Scope Statements: Imperatives for Evaluating Theory." American Sociological Review 50:288-301. https : //doi .org/10 . 2307/2095540

Willer, David. 1984. "Analysis and Composition as Theoretic Procedures." Journal of Mathematical Sociology 10:241-70. https: //doi .org/10.1080/0022250X . 1984.9989971

Willer, David. (ed.) 1999. Network Exchange Theory. Westport, CT: Praeger.

Willer, David, and Pamela Emanuelson. 2008. "Testing Ten Theories." Journal of Mathematical Sociology 32: 165-203. https://doi .org/10.1080/00222500802148743

Willer, David, Eric Gladstone, and Nick Berigan. 2013. "Social Values and Social Structure." Journal of Mathematical Sociology 37:113-130. https : //doi . org/10 . 1080/0022250X . 2011. 629067

Acknowledgements: This research was funded by an NSF grant to David Willer.

Patricia Danielle Lewis: Department of Sociology, University of South Carolina. E-mail: p.danielle.lewis@gmail.com.

David Willer: Department of Sociology, University of South Carolina.

E-mail: Willer@mailbox.sc.edu. 